Check for updates

Swansea University Medical School, Swansea, UK

2 Centre for Mental Health, University of Melbourne, Australia

3 National Institute of Health Research Biomedical Research Centre University Hospitals Bristol and Weston NHS Foundation Trust, University of Bristol, Bristol, UK

4 National Confidential Inquiry into Suicide and Safety in Mental Health, University of Manchester, UK

5 Samaritans, UK

Correspondence to: A John a.john@swansea.ac.uk Cite this as: BMJ 2020;371:m4352 http://dx.doi.org/10.1136/bmj.m4352 Published: 12 November 2020

\section{Trends in suicide during the covid-19 pandemic}

\author{
Prevention must be prioritised while we wait for a clearer picture \\ Ann John, ${ }^{1}$ Jane Pirkis, ${ }^{2}$ David Gunnell, ${ }^{3}$ Louis Appleby, ${ }^{4}$ Jacqui Morrissey ${ }^{5}$
}

As many countries face new stay-at-home restrictions to curb the spread of covid-19, there are concerns that rates of suicide may increase-or have already increased. ${ }^{12}$ Several factors underpin these concerns, including a deterioration in population mental health, ${ }^{3}$ a higher prevalence of reported thoughts and behaviours of self-harmamong people with covid-19, ${ }^{4}$ problems accessing mental health services, ${ }^{4}$ and evidence suggesting that previous epidemics such as SARS (2003) were associated with a rise in deaths by suicide. ${ }^{5}$

Widely reported studies modelling the effect of the covid-19 pandemic on suicide rates predicted increases ranging from $1 \%$ to $145 \%,{ }^{6}$ largely reflecting variation in underlying assumptions. Particular emphasis has been given to the effect of the pandemic on children and young people. Numerous surveys have highlighted that their mental health has been disproportionately affected, relative to older adults, 37 and some suggest an increase in suicidal thoughts and self-harm. ${ }^{8}$

Supposition, however, is no replacement for evidence. Timely data on rates of suicide are vital, and for some months we have been tracking and reviewing relevant studies for a living systematic review. ${ }^{6}$ The first version in June found no robust epidemiological studies with suicide as an outcome, but several studies reporting suicide trends have emerged more recently. Overall, the literature on the effect of covid-19 on suicide should be interpreted with caution. Most of the available publications are preprints, letters (neither is peer reviewed), $9^{-11}$ or commentaries using news reports of deaths by suicide as the data source. ${ }^{12}$

Nevertheless, a reasonably consistent picture is beginning to emerge from high income countries. Reports suggest either no rise in suicide rates (Massachusetts, USA ${ }^{11}$; Victoria, Australia ${ }^{13}$; England ${ }^{14}$ ) or a fall (Japan, ${ }^{9}$ Norway $^{15}$ ) in the early months of the pandemic. The picture is much less clear in low income countries, where the safety nets available in better resourced settings may be lacking. News reports of police data from Nepal suggest a rise in suicides, ${ }^{12}$ whereas an analysis of data from Peru suggests the opposite. ${ }^{10}$

Any change in the risk of suicide associated with covid-19 is likely to be dynamic. The $20 \%$ decrease in Japan early in the pandemic seemed to reverse in August, when a $7.7 \%$ rise was reported. ${ }^{9}$ Evidence from previous epidemics suggests a short term decrease in suicide can occur initially-possibly linked to a "honeymoon period" or "pulling together" phenomenon. ${ }^{5}$ Trends in certain groups may be hidden when looking at overall rates, and the National Child Mortality Database has identified a concerning signal that deaths by suicide among under 18 s may have increased during the first phase of lockdown in the UK. ${ }^{16}$

\section{Preventive action}

We must remain alert to emerging risk factors for suicide but also recognise how known risk factors may be exacerbated-and existing trends and inequalities entrenched-by the pandemic. In 2019, suicide rates among men in England and Wales were the highest since 2000, and although suicide in young people is relatively rare, rates have been rising in 10-24 year olds since 2010. ${ }^{17}$

Tackling known risk factors that are likely to be exacerbated by the pandemic is crucial. These include depression, post-traumatic stress disorder, hopelessness, feelings of entrapment and burdensomeness, substance misuse, loneliness, domestic violence, child neglect or abuse, unemployment, and other financial insecurity. ${ }^{15}$

Appropriate services must be made available for people in crisis and those with new or existing mental health problems. ${ }^{14}$ Of greatest concern, is the effect of economic damage from the pandemic. One study reported that after the 2008 economic crisis, rates of suicide increased in two thirds of the 54 countries studied, particularly among men and in countries with higher job losses. ${ }^{18}$

Appropriate safety nets must be put in place or strengthened for people facing financial hardship, along with active labour market policies to help people who are unemployed obtain work.Responsible media reporting also has a role: promoting the importance of mental health support, signposting sources of help, reporting stories of hope and recovery, and avoiding alarmist and speculative headlines that may heighten risk of suicide. ${ }^{19} 20$

It is still too early to say what the ultimate effect of the pandemic will be on suicide rates. Data so far provide some reassurance, but the overall picture is complex. The pandemic has had variable effects globally, within countries and across communities, so a universal effect on suicide rates is unlikely. The impact on suicide will vary over time and differ according to national gross domestic product and individual characteristics such as socioeconomic position, ethnicity, and mental health.

One guiding principle, however, is that suicide is preventable, and action should be taken now to protect people's mental health. We must remain vigilant and responsive, sharing evidence early and internationally (such as in the International Covid-19 Suicide Prevention Research Collaboration ${ }^{21}$ ) in these evolving uncertain times. 
Competing interests: The BMJ has judged that there are no disqualifying financial ties to commercial companies. The authors declare the following other interests: Al chairs the Welsh government's National Advisory Group on Suicide and Self-harm Prevention. DG is a member of the National Suicide Prevention Strategy Advisory Group (England) and Samaritans policy and research committee. LA is co-chair of the National Suicide Prevention Strategy Advisory Group (England).

Provenance and peer review: Commissioned; not externally peer reviewed.

1 Gunnell D, Appleby L, Arensman E, etalCOVID-19 Suicide Prevention Research Collaboration. Suicide risk and prevention during the COVID-19 pandemic. Lancet Psychiatry 2020;7:468-71. doi: 10.1016/S2215-0366(20)30171-1 pmid: 32330430

2 Reger MA, Stanley IH, Joiner TE. Suicide mortality and coronavirus disease 2019: a perfect storm?JAMA Psychiatry 2020. [Epub ahead of print.] doi: 10.1001/jamapsychiatry.2020.1060 pmid: 32275300

3 Pierce M, Hope H, Ford T, etal. Mental health before and during the COVID-19 pandemic: a longitudinal probability sample survey of the UK population. Lancet Psychiatry 2020;7:883-92 doi: 10.1016/S2215-0366(20)30308-4 pmid: 32707037

4 lob E, Steptoe A, Fancourt D. Abuse, self-harm and suicidal ideation in the UK during the COVID-19 pandemic. Br J Psychiatry 2020;217:543-6. doi: 10.1192/bjp.2020.130 pmid: 32654678

5 Zortea TC, Brenna CTA, Joyce M, etal. The impact of infectious disease-related public health emergencies on suicide, suicidal behavior, and suicidal thoughts: a systematic review. Crisis 2020:1-14. [Epub ahead of print.] doi: 10.1027/0227-5910/a000753 pmid: 33063542

6 John A, Okolie C, Eyles E, etal. The impact of the COVID-19 pandemic on self-harm and suicidal behaviour: a living systematic review. F1000 Res 2020;9:1097doi: 10.12688/f1000research.25522.1

7 O'Connor RC, Wetherall K, Cleare S, etal. Mental health and wellbeing during the COVID-19 pandemic: longitudinal analyses of adults in the UK COVID-19 Mental Health \& Wellbeing study. Br J Psychiatry 2020:1-17. [Epub ahead of print.] doi: 10.1192/bjp.2020.212. pmid: 33081860

8 Zhang L, Zhang D, Fang J, Wan Y, Tao F, Sun Y. Assessment of mental health of Chinese primary school students before and after school closing and opening during the covid-19 pandemic. JAMA Netw Open 2020;3:e2021482. doi: 10.1001/jamanetworkopen.2020.21482 pmid: 32915233

9 Ueda M, Nordström R, Matsubayashi T. Suicide and mental health during the COVID-19 pandemic in Japan.medRxiv 2020 [Preprint.] doi: 10.1101/2020.10.06.20207530

10 Calderon-Anyosa R, Kaufman J. Impact of COVID-19 lockdown policy on homicide, suicide, and motor vehicle deaths in Peru.medRxiv 2020.[Preprint.] doi: 10.1101/2020.07.11.20150193

11 Faust J, Shah S, Du C, Li S, Lin Z, Krumholz H. Suicide deaths during the stay-at-home advisory in Massachusetts.medRxiv 2020. [Preprint.] doi: 10.1101/2020.10.20.20215343

12 Pokhrel S, Sedhai YR, Atreya A. An increase in suicides amidst the coronavirus disease 2019 pandemic in Nepal. Med Sci Law 2020:25802420966501. doi: $10.1177 / 0025802420966501$ pmid: 33036544

13 Coroners Court of Victoria. Coroners Court monthly suicide data report. Report 2 https://www.coronerscourt.vic.gov.au/sites/default/files/2020-10/Coroners\%20Court\%20Suicide\%20Data\%20Report\%20-\%20Report\%202\%20-\%2005102020.pdf

14 National Confidential Inquiry into Suicide and Safety in Mental Health. Suicide in England since the COVID-19 pandemic- early figures from real-time surveillance. 2020. http://documents.manchester.ac.uk/display.aspx?DoclD=51861

15 Qin P, Mehlum L. National observation of death by suicide in the first 3 months under COVID-19 pandemic. Acta Psychiatr Scand 2020.pmid: 33111325

16 National Child Mortality Database. Child suicide rates during the covid-19 pandemic in England: real-time surveillance. 2020. https://www.ncmd.info/wp-content/uploads/2020/07/REF2532020-NCMD-Summary-Report-on-Child-Suicide-July-2020.pdf

17 lacobucci G. Suicide rates continue to rise in England and Wales. BMJ2020;370:m3431. doi: 10.1136/bmi.m3431 pmid: 32883661

18 Chang SS, Stuckler D, Yip P, Gunnell D. Impact of 2008 global economic crisis on suicide: time trend study in 54 countries. BMJ2013;347:f5239. doi: 10.1136/bmj.f5239 pmid: 24046155

19 Niederkrotenthaler T, Voracek M, Herberth A, etal. Role of media reports in completed and prevented suicide: Werther v. Papageno effects. Br J Psychiatry 2010;197:234-43. doi: 10.1192/bjp.bp.109.074633 pmid: 20807970

20 Hawton K, Marzano L, Fraser L, Hawley M, Harris E, Lainez Y. Reporting on suicidal behaviour and covid-19-need for caution. Lancet Psychiatry 2020. doi: 10.1016/S2215-0366(20)30484-3.

21 International Covid-19 Suicide Prevention Research Collaboration. https://www.iasp.info/COVID19_suicide_research.php.

This article is made freely available for use in accordance with BMJ's website terms and conditions for the duration of the covid-19 pandemic or until otherwise determined by BMJ. You may use, download and print the article for any lawful, non-commercial purpose (including text and data mining) provided that all copyright notices and trade marks are retained. 